\title{
Angiopoietin-like protein 4 improves glucose tolerance and insulin resistance but induces liver steatosis in high-fat-diet mice
}

\author{
YI WANG $^{1 *}$, LI-MING LIU ${ }^{2 *}$, LI WEI $^{3}$, WEI-WEI YE ${ }^{1}$, XIANG-YING MENG $^{1}$, \\ FENG CHEN $^{1}$, QIAN XIAO ${ }^{1}$, JIAN-YANG CHEN $^{1}$ and YONG ZHOU ${ }^{1}$
}

\author{
${ }^{1}$ Department of Endocrinology, Dahua Hospital of Xuhui District, Shanghai 200237; ${ }^{2}$ Department of General Surgery, \\ Tongji Hospital, Tongji University School of Medicine, Shanghai 200065; ${ }^{3}$ Department of Endocrinology, \\ Sixth People's Hospital Affiliated to Shanghai Jiaotong University, Shanghai 200025, P.R. China
}

Received June 19, 2015; Accepted July 21, 2016

DOI: $10.3892 / \mathrm{mmr} .2016 .5637$

\begin{abstract}
Angiopoietin-like protein 4 (Angptl4) is a secreted protein predominantly expressed in liver and adipose tissues, and has been identified as an adipokine. Angptl4 is the target gene of peroxisome proliferator-activated receptors, which are widely used as lipid-lowering and anti-diabetic drugs, and previous studies have demonstrated that Angptl4 is able to directly stimulate adipocyte lipolysis. The current study focused on how Angptl4 was involved in regulating lipid and glucose metabolism in high-fat-diet (HFD) C57 mice. In the present study, mice were divided into three groups, with standard chow mice as a normal control, adenovirus (adv)-injected HFD mice as a model control and adv-Angptl4-injected HFD mice as the Angptl4+ group. Firstly, compared with the normal control group, mice in the model control group gained more body weight with severe liver steatosis and increased serum levels of triglyceride, total cholesterol, free fatty acids, alanine aminotransferase and aspartate aminotransferase. In the Angptl1 ${ }^{+}$group, Angptl4 reduced the weight growth rate, aggravated hepatic steatosis and further increased all the aforementioned serum indexes. Secondly, compared with the normal control, the model control group had a reduced glucose tolerance and developed insulin resistance. Angptl4 expression and the phosphorylation levels of several insulin signaling pathway-associated genes, insulin receptor substrate 1, protein kinase $\mathrm{B}$, janus kinase 2 , signal transducer and activator of transcription 3 were downregulated in the liver samples. Adv-Angptl4 injection was observed to improve glucose tolerance and insulin resistance. The genes measured were
\end{abstract}

Correspondence to: Professor Yong Zhou, Department of Endocrinology, Dahua Hospital in Shanghai Xuhui, 903 Laohumin Road, Shanghai 200237, P.R. China

E-mail: shzhouyy@163.com

${ }^{*}$ Contributed equally

Key words: Angpt14, high-fat-diet, lipid and glucose metabolism, insulin resistance, insulin signaling pathway identified to be upregulated close to normal levels. All the results suggested that Angpt14 served an important role in lipid and glucose metabolism in HFD-induced obese mice, and this may have a great significance for treatment of hyperlipidemia, diabetes, metabolic syndrome and other diseases.

\section{Introduction}

The development of obesity is an international problem. Abnormal secretion of adipokines, excessive deposition of adipose cells in addition to a significant increase in intracellular lipid serve causative roles in obesity; adipokines are currently regarded as important factors in this process. As bioactive peptides, adipokines are critically involved in the energy metabolism and systemic insulin sensitivity. Various adipokines have been demonstrated to be associated with insulin resistance, obesity, type 2 diabetes and thrombotic diseases (1), for example, leptin and adiponectin, which possess numerous beneficial functions on obesity, in particular leptin, which is widely regarded as an anti-obesity hormone (2). Adiponectin on the other hand is an insulin-sensitizing adipokine, with direct antidiabetic, anti-atherogenic and anti-inflammatory functions (3).

Angiopoietin-like protein 4 (Angptl4) is an adipokine and it is predominantly expressed in the liver and adipose tissue, and is also termed peroxisome proliferator-activated receptor $\gamma$ (PPAR $\gamma$ ) angiopoietin-related protein, fasting-induced adipose factor, or hepatic fibrinogen-related protein (4). Previous studies on Angptl4 have researched lipid and glucose metabolism. For example, the expression of Angptl4 was observed to be increased in a fasted state, when compared with the fed state, implying that Angptl4 protein is associated with the to lipid metabolism (5). In addition, it has been reported that the blood lipid levels were reduced in Angptl4 knockout mice, and significantly increased with ectopic Angpt14 overexpression (6,7). Furthermore, in white adipose tissue, Angptl4 additionally promotes the expression of genes involved in triglyceride (TG) hydrolysis and the lipolytic release of free fatty acids (FFA), in addition to inhibiting the expression of lipoprotein lipase $(8,9)$. The effects of Angptl4 on the glucose metabolism have also been reported. Overexpression of Angpt14 contributes to high 
hepatic glycogen content in mice, suggesting that Angptl4 may enhance insulin sensitivity in the liver tissues (10). In addition, Le Jan et al (11) demonstrated that Angptl4 is able to significantly enhance the ability of insulin to suppress the output of hepatic glucose, and they suggested that this may be one of the numerous mechanisms by which Angptl4 reduces blood glucose. Similarly, Xu et al (12) indicated that Angptl4 can reduce blood glucose and improve glucose tolerance, thus suggesting that Angptl4 is able to increase insulin sensitivity and improve insulin resistance.

Regardless of the previous studies on Angptl4, the long-term effects of this protein on the energy metabolism and insulin sensitivity remain to fully elucidated. In the current study, an adenovirus-mediated expression system was used to investigate the metabolic effects of Angptl4 on high-fat-diet (HFD)-induced obese mice. The results provided evidence that Angptl4 is able to improve glucose tolerance in the HFD-induced obese mice, however promotes hepatic steatosis and lipolysis, which are in agreement with previous studies $(12,13)$. In addition, with normal diet mice as a control, the phosphorylation levels of several insulin signaling pathway-related genes were observed to be significantly downregulated in HFD-induced obese mice, whereas were upregulated in HFD-induced obese mice with adenovirus-mediated expression of Angpt14.

\section{Materials and methods}

Construction of adenoviral vector for overexpression of Angptl4. The adenovirus expression vector was generated using the AdMax ${ }^{\mathrm{TM}}$ Expression System (Microbix Biosystems, Inc., Mississauga, ON, Canada). The shuttle and adenoviral backbone plasmid pDC315 carrying a loxP expression cassette in the $\mathrm{E}_{1}$ region was purchased from Addgene, Inc. (Cambridge, MA, USA). The recombinant plasmid pDC315-Angptl4 was constructed by restriction enzyme (EcoRI and $B a m \mathrm{HI})$ cleavage and connection. The plasmid pBHG lox $\Delta \mathrm{E}_{1,3}$ Cre containing the Cre/loxP element was purchased from Microbix Biosystems, Inc. The recombinant adenoviral-Angptl4 (adv-Angptl4) virus was packaged, amplified in HEK293 cells and then purified by $\mathrm{CsCl}$ density gradient centrifugation at $100,000 \mathrm{x}$ g for $16 \mathrm{~h}$ at $4^{\circ} \mathrm{C}$.

Grouping of animals. A total of 24 male C57BL/6 healthy mice between 8 and 10 weeks old $(\sim 20 \mathrm{~g})$ were obtained from the Shanghai Experimental Animal Center, Chinese Academy of Sciences (Shanghai, China) and were housed in a room under controlled temperature $\left(23 \pm 1^{\circ} \mathrm{C}\right)$ with free access to water. Mice were fed standard chow for the first week to allow them to adjust to the new environment. Subsequently, mice were divided into three groups randomly. As a control, mice in the first group (normal control) were fed with standard mouse chow. The other two groups were provided with a HFD for 6 weeks, and then adenoviral (adv) and adv-Angptl4 virus were injected via the tail vein in the second (model control) and third (Angptl4 ${ }^{+}$) groups of mice, respectively. The normal control group continued to be fed with standard chow, whereas the model control and Angpt14+ groups were fed with HFD for an additional two weeks. The mice in the three groups were weighed once a week subsequent to injection with the virus. Two weeks after viral injection, a series of experiments were performed. All of the experiments were conducted under institutional guidelines for the humane treatment of laboratory animals, and the study was approved by the ethics committee of Dahua Hospital in Shanghai Xuhui (Shanghai, China).

Measurement of Angptl4 in mouse serum. Serum Angptl4 concentrations of the three groups of mice were measured using a sandwich enzyme-linked immunosorbent assay, with the experimental kit purchased from JRDUN Biotechnology, Co., Ltd. (Shanghai, China).

Oral glucose tolerance test. All mice were placed into other clean cages with free access to water, however no food, for $6 \mathrm{~h}$. Subsequent to fasting, the mice were weighed, the tip of the tails were clipped in order to obtain blood, and the fasting blood glucose levels were measured with the OneTouch small glucometer. Mice were then rapidly administered with an intraperitoneal injection of glucose ( $1 \mathrm{~g} / \mathrm{kg}$ of body weight). Blood was drawn from the mice tail tip at various time points: T15, T30, T60, T90, T120 and T150 min for measurement of glucose concentration.

Analysis of TG, total cholesterol (TC), alanine aminotransferase (ALT), aspartate aminotransferase (AST), FFA and fasting insulin (FIN) in mice serum. The serum levels of TG and TC were detected by an enzyme-coupled assay, the ALT and AST levels were detected by the Reitman-Frankel method (14), FFA levels were detected using the Copper Color Method with a semi-automatic or fully-automatic spectrophotometer. All of the serum indices were measured using the kit from Nanjing Jiancheng Bioengineering Institute (Nanjing, China). The serum levels of fasting FIN were detected using the ${ }^{125} \mathrm{I}$-insulin radio immunoassay kit from the North Biotechnology Institute (Beijing, China). The homeostasis model assessment of insulin resistance (HOMA-IR) was calculated using the following formula: Fasting blood glucose (FBG; mmol/l) x FIN ( $\mu \mathrm{IU} / \mathrm{ml}) / 22.5$. Subsequently, the data were logarithmically transformed in order to obtain a more accurate value.

Hematoxylin/eosin (HE) staining of liver paraffin-embedded sections. Tissue blocks of livers were resected and fixed in $10 \%$ formalin for $48 \mathrm{~h}$, then were embedded in paraffin. Subsequently, they were sectioned and stained with HE. Finally, the degree of steatosis and inflammation were analyzed under a light microscope (magnification, $\mathrm{x} 100)$.

Western blot analysis. Mice were sacrificed by $\mathrm{CO}_{2}$ inhalation, then fresh liver tissue samples were obtained from the mice in the process of dissecting the mice. The liver tissues ( $100 \mathrm{mg})$ were rapidly weighed, and the tissues were pulverized in a mortar using liquid nitrogen. Radioimmunoprecipitation assay (RIPA) lysis buffer was then added ( $3 \mathrm{ml} \mathrm{RIPA/gram} \mathrm{of} \mathrm{tissue)} \mathrm{premixed} \mathrm{with}$ proteinase and phosphatase inhibitors. The concentration of liver tissue protein was quantified using the Bicinchoninic 
Acid kit (Thermo Fisher Scientific, Inc., Waltham, MA, USA). A total of $80 \mu \mathrm{g}$ protein for each sample was loaded and underwent $10 / 15 \%$ sodium dodecyl sulfate-polyacrylimide gel electrophoresis for separation. The blots were blocked with $5 \%$ non-fat milk at room temperature for $1 \mathrm{~h}$ and were incubated overnight at $4{ }^{\circ} \mathrm{C}$ with the following primary antibodies: Polyclonal rabbit Angptl4 (bs-1087R; 1:100; Bioss, Inc., Woburn, MA, USA), monoclonal rabbit janus kinase 2 (JAK2) (\#3230; 1:1,000; Cell Signaling Technology, Inc., Danvers, MA, USA), rabbit monoclonal phosphorylated (P-) JAK2 (\#8082; 1:1,000; Cell Signaling Technology, Inc.), rabbit polyclonal insulin receptor substrate 1 (IRS-1) (\#2382; 1:1,000; Cell Signaling Technology, Inc.), rabbit polyclonal P-IRS-1 (\#2381; 1:1,000; Cell Signaling Technology, Inc.), mouse monoclonal signal transducer and activator of transcription 3 (STAT3) (ab119352; 1:5,000; Abcam, Cambridge, MA, USA); rabbit monoclonal P-STAT3 (ab76315, 1:200,000; Abcam), rabbit polyclonal protein kinase B (AKT) (\#9272; 1:1,000; Cell Signaling Technology, Inc.); rabbit polyclonal P-AKT (\#9271; 1:1,000; Cell Signaling Technology, Inc.), rabbit monoclonal glyceraldehyde 3-phosphate dehydrogenase (GAPDH) (\#5174; 1:1,000; Cell Signaling Technology, Inc.). In order to ensure equal amount of protein loaded, levels were normalized to that of GAPDH. The blots were incubated for $1 \mathrm{~h}$ at $37^{\circ} \mathrm{C}$ temperature with the goat anti-rabbit (A0208) and goat anti-mouse (A0216) polyclonal secondary antibodies (conjugated with horseradish peroxidase; 1:1,000; Beyotime Institute of Biotechnology, Shanghai, China) following three washes with Tris-buffered saline with Tween-20 (TBST) buffer. The signals were visualized using enhanced chemiluminescence (EMD Millipore, Billerica, MA, USA) following an additional wash with TBST. Intensities were measured using ImageJ software, version 1.4 (National Institutes of Health, Bethesda, MD, USA) and were reported as the relative pixel normalized to that of GAPDH.

Statistical analysis. Experiments were performed with eight mice per group with values expressed as the mean \pm standard deviation. Statistical analysis was determined using one-way analysis of variance with Graphpad Prism software, version 6.0. $\mathrm{P}<0.05$ was considered to indicate a statistically significant difference.

\section{Results}

Expression of Angptl4 protein in HFD C57 mice following tail-vein injection with adv-Angptl4. In order to verify the role of Angptl4 as a circulating hormone in mice subsequent to viral injection, a sandwich enzyme-linked immunoassay was conducted for measurement of the protein in mouse serum. Serum Angpt14 concentrations in the normal and model control groups were not significantly different, with values of $2.44 \pm 0.32 \mathrm{ng} / \mathrm{ml}$ and $2.24 \pm 0.21 \mathrm{ng} / \mathrm{ml}$, respectively. The serum concentration in the Angptl $4^{+}$group was increased compared with that of the control groups, with a concentration of $3.86 \pm 0.24 \mathrm{ng} / \mathrm{ml}$ (Fig. 1). These results suggested that the recombinant adv-Angpt14 virus had been constructed successfully, and that the Angptl4 gene was highly expressed in HFD mice.

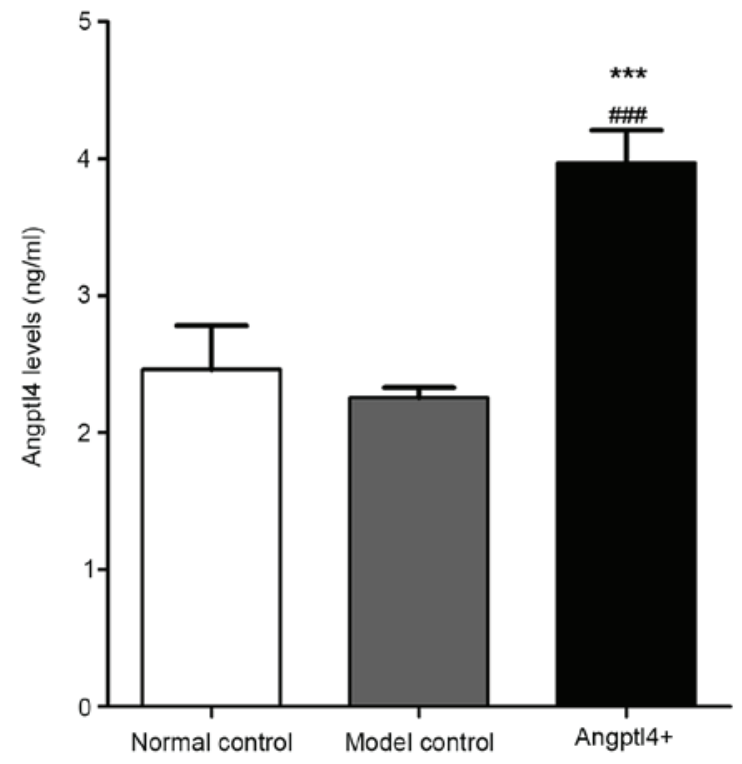

Figure 1. Expression of Angpt14 protein in C57 mice following tail-vein injection with adenoviral-Angptl4. The data are presented as the mean \pm standard deviation; $\mathrm{n}=8 ;{ }^{* * *} \mathrm{P}<0.001$ vs. normal control group; ${ }^{\# \#} \mathrm{P}<0.001$ vs. model control group. Angptl4, angiopoietin-like protein 4.

Angptl4 overexpression reduces body weight and markedly elevates the serum levels of TC, TG and FFA in HFD mice. A week subsequent to the injection of the virus, no significant differences were observed between the model control and Angptl1 ${ }^{+}$groups. After two weeks, in the model control group, a significant increase in body weight was observed, with the mice weighing $28 \pm 1.07 \mathrm{~g}$ at the end of the experiment, with an increase ratio of $20.4 \%$, markedly higher than that of the normal control group. However, Angpt14 reduced the weight growth rate in HFD mice, with an increase of $10.5 \%$, weighing $26.13 \pm 0.64 \mathrm{~g}$ (Fig. 2A). The levels of serum indices TG, TC and FFA associated with blood lipids were detected, and the results indicated that all index levels in the Angpt $14^{+}$group were significantly increased compared with that of the control groups. The levels in the model control were significantly higher than that of the normal control group (Fig. 2B-D).

Angpt14 overexpression reduced the weight growth rate almost by half in HFD mice, and significantly increased the levels of the major serum indices in the serum of HFD mice, suggesting that subsequent to infection with Angptl4 in HFD mice, the blood lipid levels and lipolysis were increased, which may have directly induced hyperlipidemia.

Angptl4 overexpression promotes liver steatosis and markedly elevates the serum levels of ALT and AST in HFD mice. In order to investigate the influence of Angptl4 on liver function in HFD mice, HE staining was conducted in paraffin-embedded liver tissue sections from the three groups. The levels of ALT and AST, which are associated with liver function, were detected. The results indicated that hepatocyte swelling occurred in the livers of model control mice, together with increased vacuolization in the liver cytoplasm. It is notable that the swelling was more marked with larger fat vacuoles visible in the liver cytoplasm in the 
A

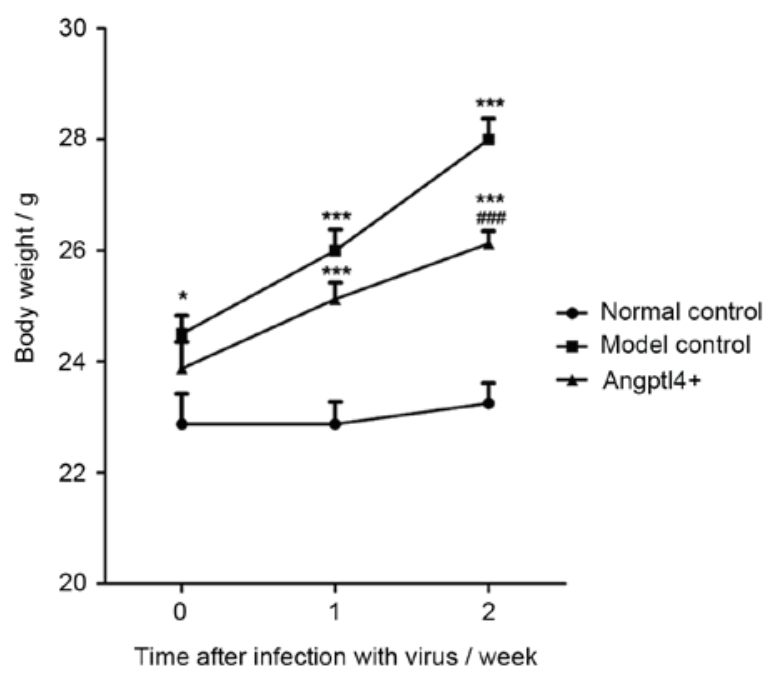

C

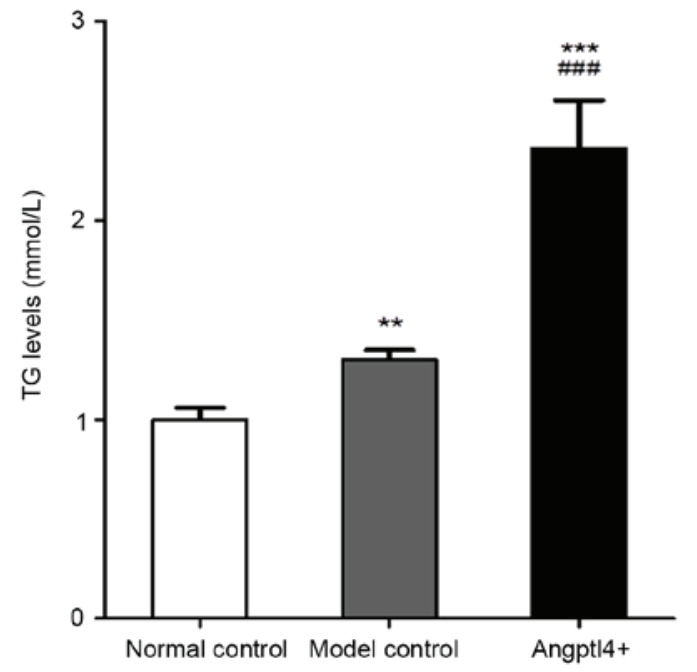

B

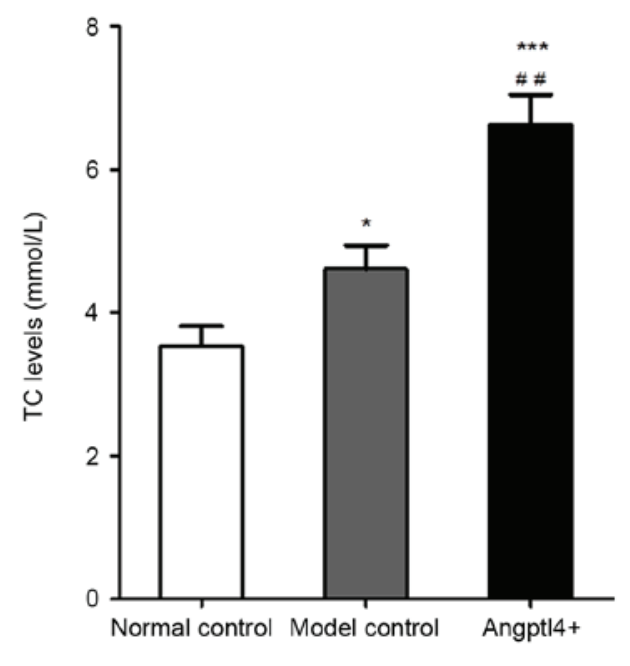

D

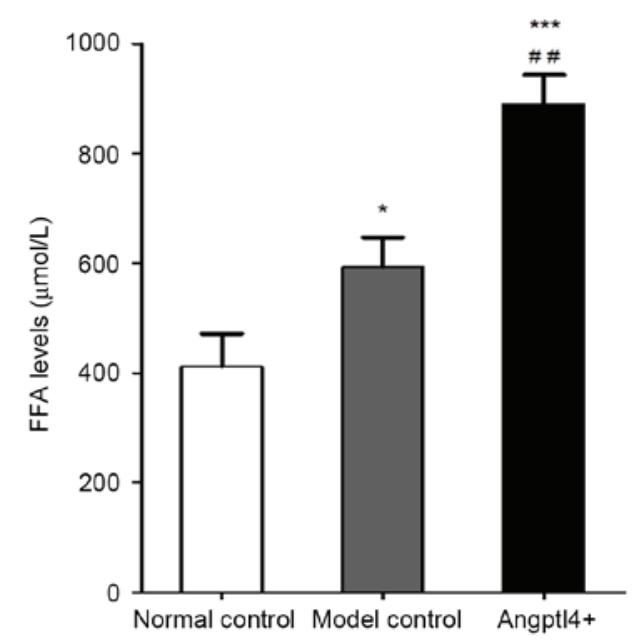

Figure 2. (A) Impact of Angpt14 on body weight of high-fat-diet mice. (B) The levels of TC in three groups. (C) The levels of TG in three groups. (D) The levels of FFA in three groups. Data are presented as the mean \pm standard deviation; $n=8 .{ }^{*} \mathrm{P}<0.05,{ }^{* *} \mathrm{P}<0.01,{ }^{* * * *} \mathrm{P}<0.001$ vs. normal control group; ${ }^{\# \#} \mathrm{P}<0.01,{ }^{\# \# \#} \mathrm{P}<0.001$ vs. model control group. Angpt14, angiopoietin-like protein 4; TC, total cholesterol; TG, triglyceride; FFA, free fatty acids.

Angptl $4^{+}$group (Fig. 3A). The ALT and AST levels in the model control group were marginally upregulated, whereas were significantly increased in the Angptl $4^{+}$group, with the normal control group as the control (Fig. 3B and C).

All results indicated that overexpression of Angptl4 serves a negative role in liver steatosis in HFD, and resulted in damage to liver function of HFD mice.

Angptl4 overexpression potently improves glucose tolerance in HFD mice. To validate the effect of Angptl4 on blood glucose levels, the glucose tolerance of the three groups was investigated. With the normal control group mice as a control, it was identified that the model control group mice exhibited a rise in blood glucose levels throughout the glucose tolerance curve and a maximum glucose concentration at $60 \mathrm{~min}$. This increase was present, but less marked in the Angptl $4^{+}$group, with results similar to thos of the normal control. These results indicated that Angpt14 overexpression can improve glucose tolerance in HFD mice (Fig. 4).
Angptl4 overexpression alleviates the HOMA-IR levels in HFD mice. The effects of Angptl4 on FIN levels were observed, and insulin resistance was assessed in HFD mice. The results indicated that overexpression of Angpt14 markedly reduced FIN (Fig. 5A) and FBG levels (Fig. 5B). HOMA-IR was increased in the model control group, together with a lower insulin sensitivity compared with the normal control group, while these levels were reduced back to levels similar to the normal control in the Angpt14+ group (Fig. 5C), suggesting that Angptl4 can alleviate insulin resistance and enhance insulin sensitivity in HFD mice.

Angptl4 overexpression results in the downregulation of several insulin signaling pathway-associated genes in HFD mice. IRS-1 links the insulin receptor kinase and its downstream serine kinases, including phosphoinositide 3-kinase (PI3K) and AKT phosphorylation. Under the insulin resistant state, the effects of the PI3K-AKT signal transduction pathway on insulin stimulation are reduced (15). The JAK2-STAT3 
A

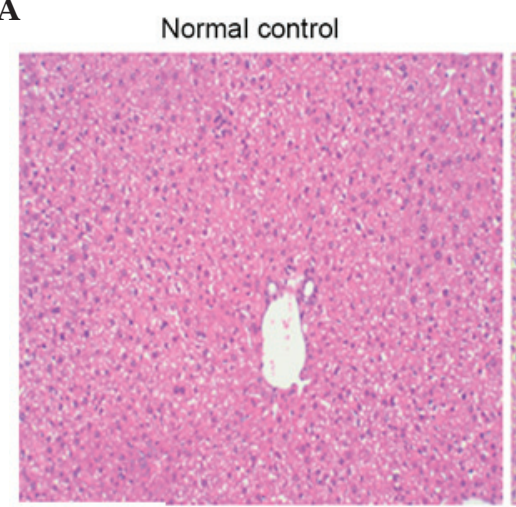

B

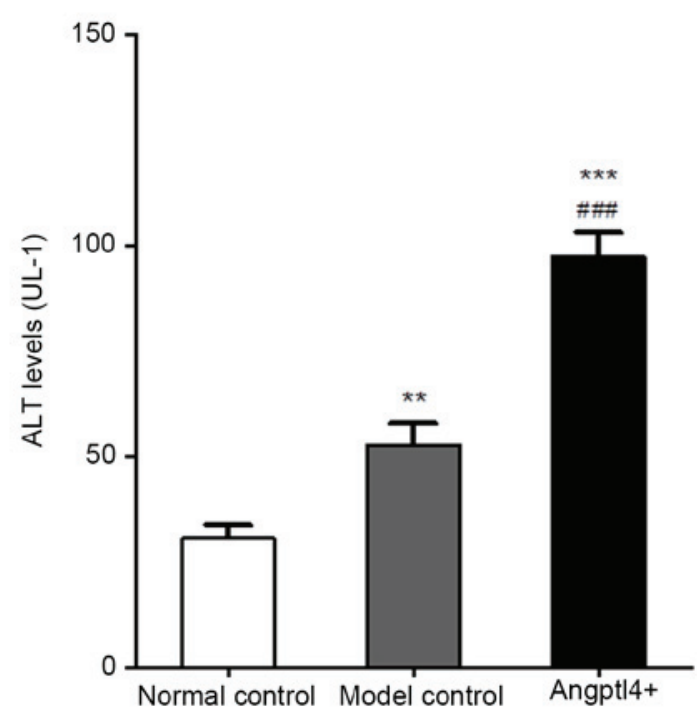

Model control

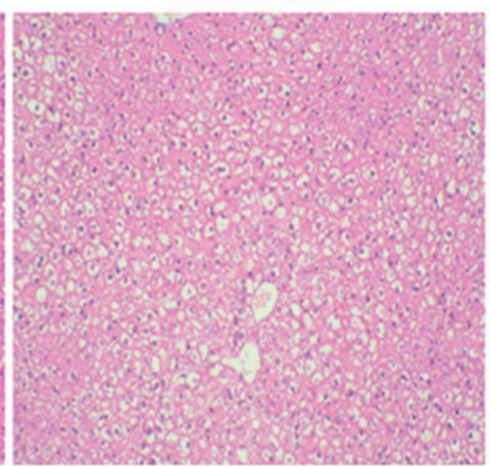

Angptl4+

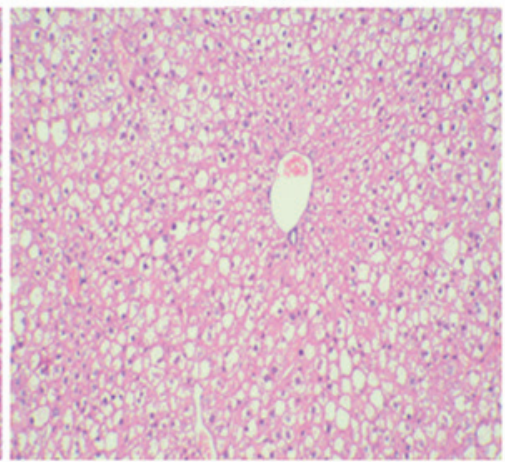

C

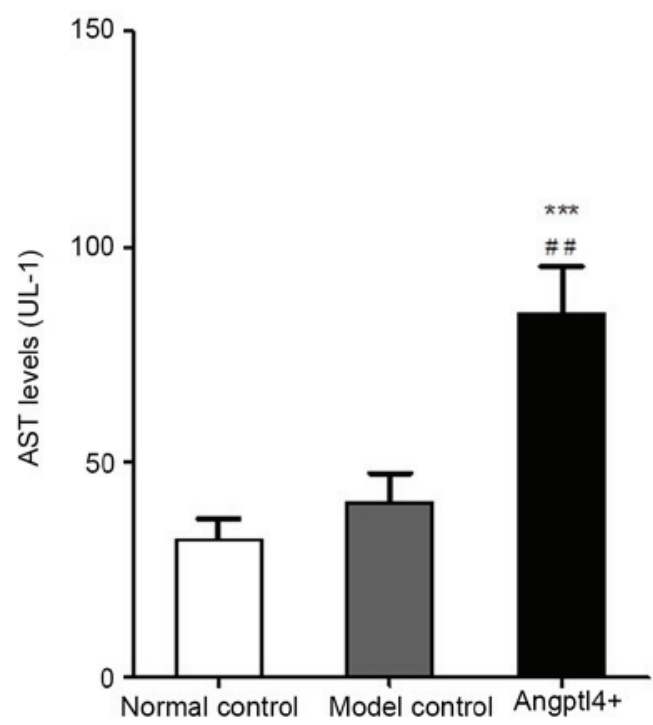

Figure 3. (A) Influence of Angpt14 on morphological characterization of denatured liver in high-fat-diet mice. (B) The levels of ALT. (C) The levels of AST in three groups. Data are presented as the mean \pm standard deviation, $\mathrm{n}=8 .{ }^{* *} \mathrm{P}<0.01,{ }^{* * *} \mathrm{P}<0.001$ vs. normal control group; ${ }^{\# \#} \mathrm{P}<0.01,{ }^{\# \# /} \mathrm{P}<0.001$ vs. model control group. Angpt14, angiopoietin-like protein 4; ALT, alanine aminotransferase; AST, aspartate aminotransferase.

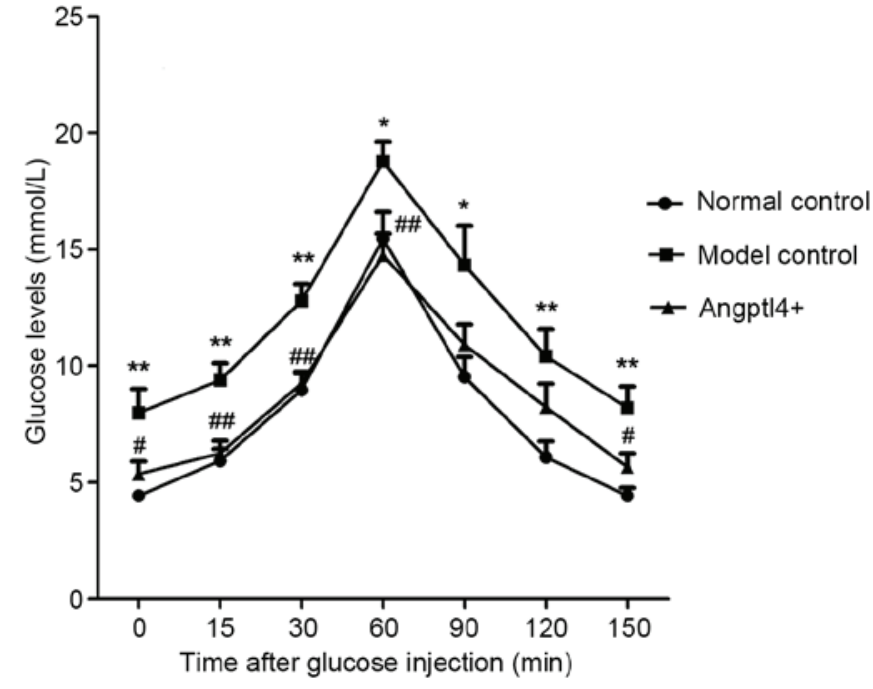

Figure 4. Effect of Angpt14 on the blood glucose concentration, measured by OGTT in high-fat-diet mice. The OGTT was performed via intraperitoneal injection with glucose $(1 \mathrm{~g} / \mathrm{kg}$ of body weight) subsequent to fasting for $6 \mathrm{~h}$, and the blood glucose levels were determined at various time points as indicated. Data were presented as the mean \pm standard deviation; $n=8$. ${ }^{*} \mathrm{P}<0.05,{ }^{* *} \mathrm{P}<0.01$ vs. normal control group; ${ }^{*} \mathrm{P}<0.05,{ }^{\# \#} \mathrm{P}<0.01$ vs. model control group. Angpt14, angiopoietin-like protein 4; OGTT, oral glucose tolerance test. signaling pathway is involved in the lipid metabolism through mediation by leptin (16). In the current study, western blot analysis was used to detected the phosphorylation levels of IRS-1, AKT, JAK2 and STAT3, in addition to expression of Angpt14, in the liver samples. The results indicated that with the normal control group as the control, the phosphorylated proteins and Angptl4 were downregulated in the model control group, however were upregulated in the in Angpt14+ group to levels similar to those of the normal control group (Fig. 6).

\section{Discussion}

Angpt14, which was originally identified as a downstream target gene of PPARs, and has been identified as an adipokine, is associated with insulin resistance, dyslipidemia, obesity, type 2 diabetes and thrombotic diseases $(3-5,17)$. The current study identified that in HFD mice, Angptl4 is a circulating hormone involved in regulating lipid and glucose homeostasis, and this protein also has an effect on systemic insulin sensitivity and the insulin signal pathway.

Overexpression of Angptl4 in HFD mice reduced the body weight of mice and stimulated the intracellular hydrolysis of TG and TC, together with the release of FFA, which result from 

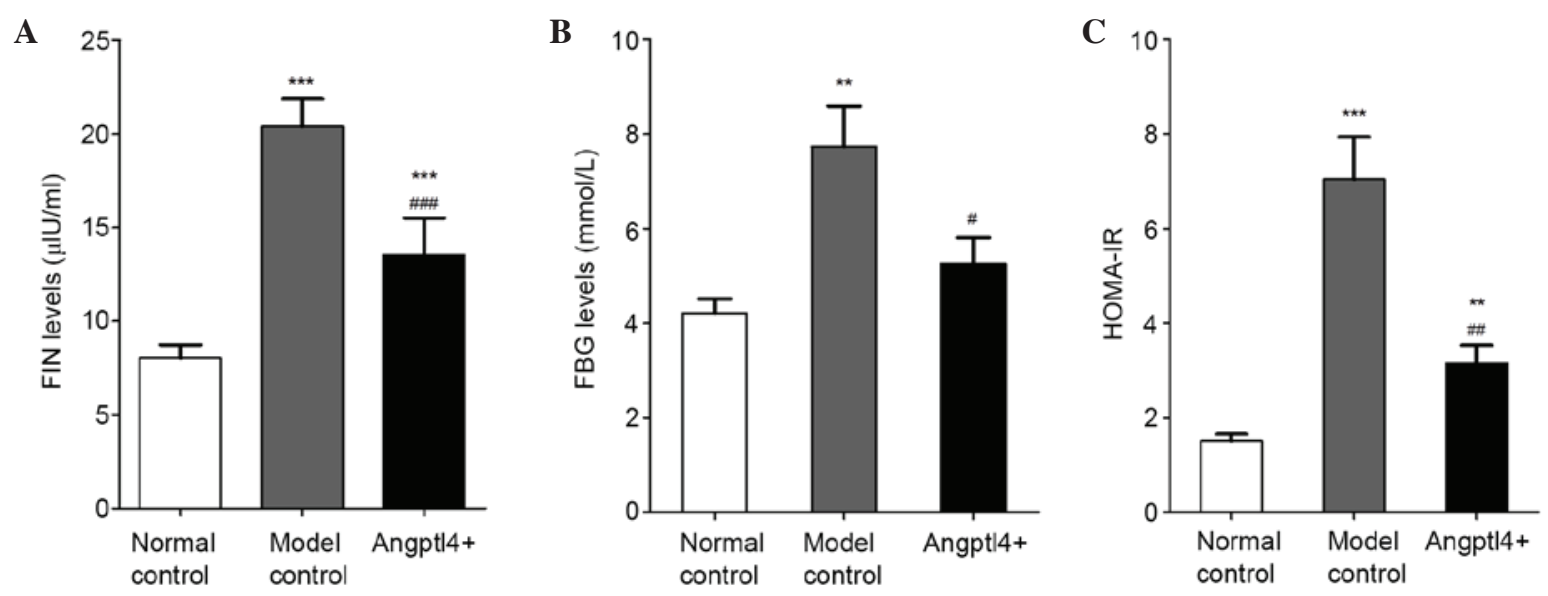

Figure 5. (A) FIN levels in the three groups. (B) FBG levels in the three groups. (C) Insulin resistance reflected by the HOMA-IR levels in the three groups. Data are presented as the mean \pm standard deviation; $n=8 .{ }^{* *} \mathrm{P}<0.01,{ }^{* * *} \mathrm{P}<0.001$ vs. normal control group; ${ }^{\#} \mathrm{P}<0.05,{ }^{\# \#} \mathrm{P}<0.01,{ }^{\# \# \#} \mathrm{P}<0.001$ vs. model control group. FIN, fasting insulin; FBG, fasting blood glucose; HOMA-IR, homeostasis model assessment of insulin resistance.

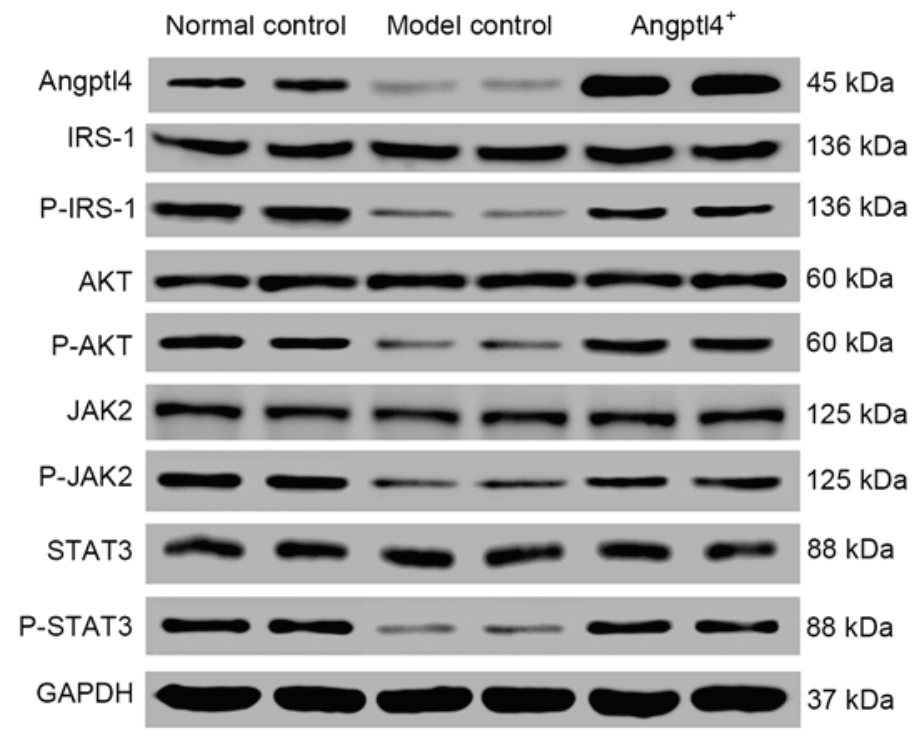

Figure 6. Angptl4 overexpression causes alterations in the levels of certain associated genes involved in the insulin signaling pathway in high-fat-diet mice. The phosphorylation levels of the four selected genes: IRS-1, AKT, JAK2 and STAT3 in the liver were observed to be downregulated in the model control group, whereas were upregulated to levels close to the normal levels in the Angptl4 ${ }^{+}$group, with the normal control group as the control. Angptl4, angiopoietin-like protein 4; IRS-1, insulin receptor substrate 1; AKT, protein kinase B; JAK2, janus kinase 2; STAT3, signal transducer and activator of transcription 3; P-, phosphorylated; GAPDH, glyceraldehyde 3-phosphate dehydrogenase.

adipolysis and may lead to dyslipidemia. The data of the current study were consistent with previous studies that indicated that Angptl4 is able to inhibit lipoprotein lipase activity, resulting in hypertriglyceridemia and further fat hydrolysis $(18,19)$. In addition, given that the adipokine Angptl4 is a downstream target gene of PPARs, it would be hypothesized to benefit from the functions of PPARs, including potent lipid-lowering, fatty acid oxidation enhancing and lipogenesis inhibiting abilities in the liver tissues (20). Lipolysis occurs to produce energy, and generally occurs in the fasted state, when there is a shortage of blood glucose. In patients with obesity and insulin resistance, lipolysis by white adipocytes is no longer restricted to the fasted state, and occurs in the fed state when insulin normally suppresses this process $(21,22)$, suggesting that HFD may induce lipolysis. Therefore, in the current study, the serum levels of TC, TG and FFA in the model control group were all increased compared with that of the normal control.

During the investigation of the effects of Angptl4 on glycometabolism, liver function, glucose tolerance and insulin resistance were additionally assessed. Gray et al (23) identified that, when purified human Angptl4 was added to cultured murine adipocytes, intracellular cyclic adenosine monophosphate levels were markedly increased, with the lipolytic impairment reversed in Angptl4-deficient cells, suggesting that it may be associated with glycometabolism. The observation that the beneficial effects of Angptl4 on glucose homeostasis and insulin resistance are associated with liver steatosis and hyperlipidemia is unexpected. However, previous studies using animal models suggest that certain signaling pathways that improve glucose homeostasis and enhance 
insulin sensitivity can simultaneously induce hyperlipidemia and liver steatosis. For example, the hepatic activation of AKT, a key signaling molecule (24), and liver-specific depletion of phosphatase and tensin homolog, a negative regulator of the PI3K/AKT pathway (25), are able to improve systemic glucose tolerance, however concurrently induce hypertriglyceridemia and liver steatosis.

The observation that HFD leads to high FIN levels, however low Angptl4 in vivo expression, is supported by previous studies demonstrating that insulin can repress the expression of Angptl4, an effect reciprocal to that of glucocorticoids (26,27). By contrast, considering the fact that abnormalities in the insulin signaling pathway are critical for the occurrence of insulin resistance $(28,29)$, the current study aimed to investigate the alterations in certain associated genes involved in the insulin signaling pathway in HFD mice. The results indicated that with the normal control group as the control, the investigated genes were downregulated in the model control group, however were upregulated in the Angptl4 ${ }^{+}$group close to the levels observed in the normal control group. This suggested that Angptl4 affects not only insulin resistance, however also the insulin signaling pathway, as hypothesized. A previous study by Hou et al (30) indicated that Angptl4 is able to induce the activation of the extracellular signal-related kinase $1 / 2$ and PI3K/AKT pathways. In addition, Angptl4 has been reported to activate JAK1/STAT3 signaling to regulate inducible nitric oxide synthase expression in keratinocytes (31). These studies are in agreement with the results of the current study. Furthermore, a recent study (32) demonstrated that obesity leads to low phosphorylation levels of JAK1 and STAT3.

In summary, Angptl4 induces obesity-associated metabolic disorders. The present study suggested that Angptl4 promotes liver steatosis and lipolysis, in addition to impairing liver function; while Angptl4 improves glucose tolerance and insulin resistance, in addition to causing the downregulation of various insulin signaling pathway-associated genes. The specific mechanisms involved in the mediation of insulin signaling pathways to affect lipid and glucose metabolism by Angptl4 remains to be fully elucidated. It is suggested that Angptl4 may be a novel therapeutic target in hyperlipidemia, diabetes, metabolic syndrome and additional diseases.

\section{Acknowledgements}

The current study was supported by grants from the projects of Shanghai Health Bureau Scientific Research (grant no. 20134126).

\section{References}

1. Kershaw EE and Flier JS: Adipose tissue as an endocrine organ. J Clin Endocrinol Metab 89: 2548-2556, 2004

2. Friedman JM and Halaas JL: Leptin and the regulation of body weight in mammals. Nature 395: 763-770, 1998.

3. Matsuzawa Y, Funahashi T, Kihara S and Shimomura I: Adiponectin and metabolic syndrome. Arterioscler Thromb Vasc Biol 24: 29-33, 2004.

4. Yoon JC, Chickering TW, Rosen ED, Dussault B, Qin Y, Soukas A, Friedman JM, Holmes WE and Spiegelman BM: Peroxisome proliferator-activated receptor gamma target genen encoding a novel angiopoietin-related protein associated with adipose differentiation. Mol Cell Biol 20: 5343-5349, 2000
5. Kersten S, Mandard S, Tan NS, Escher P, Metzger D, Chambon P, Gonzalez FJ, Desvergne B and Wahli W: Characterization of the fasting- induced adipose factor FIAF, a novel peroxisome proliferator activated receptor target gene. J Biol Chem 275: 28488-28493, 2000.

6. Koster A, Chao YB, Mosior M, Ford A, Gonzalez-DeWhitt PA, Hale JE, Li D, Qiu Y, Fraser CC, Yang DD, et al: Transgenic angiopoietin-like (angptl)4 overexpression and targeted disrupt ion of angpt14 and angpt13: Regulation of triglyceride metabolism. Endocrinology 146: 4943-4950, 2005.

7. Ge H, Cha JY, Gopal H, Harp C, Yu X, Repa JJ and Li C: Differential regulation and properties of angiopoietin-like proteins 3 and 4. J Lipid Res 46: 1484-1490, 2005.

8. Sanderson LM, Degenhardt T, Koppen A, Kalkhoven E, Desvergne B, Müller M and Kersten S: Peroxisome proliferator-activated receptor beta/delta (PPARbeta/delta) but not PPARalpha serves as a plasma free fatty acid sensor in liver. Mol Cell Biol 29: 6257-6267, 2009.

9. Mattijssen F and Kersten S: Regulation of triglyceride metabolism by Angiopoietin-like proteins. Biochim Biophys Acta 1821: 782-789, 2012.

10. Merkel M, Eckel RH and Goldberg IJ: Lipoprotein lipase: Genetics, lipid uptake, and regulation. J Lipid Res 43: 1997-2006, 2002.

11. Le Jan S, Amy C, Cazes A, Monnot C, Lamandé N, Favier J, Philippe J, Sibony M, Gasc JM, Corvol P and Germain S: Angiopoietin-like 4 is a proangiogenic factor produced during ischemia and in conventional renal cell carcinoma. Am J Pathol 162: 1521-1528, 2003.

12. Xu A, Lam MC, Chan KW, Wang Y, Zhang J, Hoo RL, Xu JY, Chen B, Chow WS, Tso AW and Lam KS: Angiopoietin-like protein 4 decreases blood glucose and improves glucose tolerance but induces hyperlipidemia and hepatic steatosis in mice. Proc Natl Acad Sci USA 102: 6086-6091, 2005.

13. Mandard S, Zandbergen F, van Straten E, Wahli W, Kuipers F, Müller M, Kersten S: The fasting-induced adipose factor/angiopoietin-like protein 4 is physically associated with lipoproteins and governs plasma lipid levels and adiposity. J Biol Chem 281: 934-944, 2006

14. Reitman S and Frankel S: A colorimetric method for the determination of serum glutamic oxalacetic and glutamic pyruvic transaminases. Am J Clin Pathol 28: 56-63, 1957.

15. Cusi K, Maezono K, Oaman A, Pendergrass M, Patti ME, Pratipanawatr T, DeFronzo RA, Kahn CR and Mandarino LJ: Insulin resistance differentially affects the pi3-kinase- and MAP kinase-mediated signaling in human muscle. J Clin Invest 105: 311-320, 2000

16. Wang WZ, Zhao SM and Gao SZ: Research progress on leptin-mediated JAK/STAT signaling pathway in lipid metabolism. Chin J Cell Biol 33: 584-589, 2011.

17. Kim HK, Youn BS, Shin MS, Namkoong C, Park KH, Baik JH, Kim JB, Park JY, Lee KU, Kim YB and Kim MS: Hypothalamic Angptl4/Fiaf is a novel regulator of food intake and body weight. Diabetes 59: 2772-2780, 2010.

18. Yoshida K, Shimizugawa T, Ono $M$ and Furukawa $H$ : Angiopoietin-like protein 4 is a potent hyperlipidemia-inducing factor in mice and inhibitor of lipoprotein lipase. J Lipid Res 43: 1770-1772, 2002

19. Oike Y, Akao M, Kubota Y and Suda T: Angiopoietin-like proteins: Potential new targets for metabolic syndrome therapy. Trends Mol Med 11: 473-479, 2005.

20. Lee CH, Olson P and Evans RM: Minireview: Lipid metabolism, metabolic diseases, and peroxisome proliferator-activated receptors. Endocrinology 144: 2201-2207, 2003.

21. Guilherme A, Virbasius JV, Puri V and Czech MP: Adipocyte dysfunctions linking obesity to insulin resistance and type 2 diabetes. Nat Rev Mol Cell Biol 9: 367-377, 2008.

22. Samuel VT, Petersen KF and Shulman GI: Lipid-induced insulin resistance: Unravelling the mechanism. Lancet 375: 2267-2277, 2010.

23. Gray NE, Lam LN, Yang K, Zhou AY, Koliwad S and Wang JC: Angiopoietin-like 4 (Angptl4) protein is a physiological mediator of intracellular lipolysis in murine adipocytes. J Biol Chem 287: 8444-8456, 2012.

24. Ono H, Shimano H, Katagiri H, Yahagi N, Sakoda H, Onishi Y, Anai M, Ogihara T, Fujishiro M, Viana AY, et al: Hepatic Akt activation induces marked hypoglycemia, hepatomegaly, and hypertriglyceridemia with sterol regulatory element binding protein involvement. Diabetes 52: 2905-2913, 2003. 
25. Stiles B, Wang Y, Stahl A, Bassilian S, Lee WP, Kim YJ, Sherwin R, Devaskar S, Lesche R, Magnuson MA and Wu H: Liver-specific deletion of negative regulator Pten results in fatty liver and insulin hypersensitivity. Proc Natl Acad Sci USA 101: 2082-2087, 2004.

26. Mizutani N, Ozaki N, Seino Y, Fukami A, Sakamoto E, Fukuyama T, Sugimura Y, Nagasaki H, Arima H and Oiso Y: Reduction of insulin signaling upregulates angiopoietin-like protein 4 through elevated free fatty acids in diabetic mice. Exp Clin Endocrinol Diabetes 120: 139-144, 2012.

27. Yamada T, Ozaki N, Kato Y, Miura Y and Oiso Y: Insulin downregulates angiopoietin-like protein 4 mRNA in 3T3-L1 adipocytes. Biochem Biophys Res Commun 347: 1138-1144, 2006.

28. Prudente S, Morini E and Trischitta V: Insulin signaling regulating genes: Effect on T2DM and cardiovascular risk. Nat Rev Endocrinol 5: 682-693, 2009.
29. Karlsson HK and Zierath JR: Insulin signaling and glucose transport in insulin resistant human skeletal muscle. Cell Biochem Biophys 48: 103-113, 2007.

30. Hou M, Cui J, Liu J, Liu F, Jiang R, Liu K, Wang Y, Yin L, Liu W and Yu B: Angiopoietin-like 4 confers resistance to hypoxia/serum deprivation-induced apoptosis through PI3K/Akt and ERK1/2 signaling pathways in mesenchymal stem cells. PLoS One 9: e85808, 2014.

31. Chong HC, Chan JS, Goh CQ, Gounko NV, Luo B, Wang X, Foo S, Wong MT, Choong C, Kersten S and Tan NS: Angiopoietin-like 4 stimulates STAT3-mediated iNOS expression and enhances angiogenesis to accelerate wound healing in diabetic mice. Mol Ther 22: 1593-1604, 2014

32. Yan ZK, Yang ZJ and Chen F: Effect of electroacupuncture stimulation of 'Housanli' (ST 36) and 'Zhongwan' (CV 12) on serum leptin and hepatocellular JAK 2-STAT 3 signaling in obese rats. Zhen Ci Yan Jiu 40: 1-5, 2015 (In Chinese). 